\title{
Long-Term Mortality of Coronary Artery Bypass Graft Surgery and Stenting with Drug-Eluting Stents
}

\author{
Chuntao Wu, MD, PhD' ${ }^{1}$, Fabian T. Camacho, MS ${ }^{1}$, Songyang Zhao, $\mathrm{MS}^{2}$, Andrew S. \\ Wechsler, MD $^{3}$, Alfred T. Culliford, MD ${ }^{4}$, Stephen J. Lahey, MD ${ }^{5}$, Spencer B. King III, MD ${ }^{6}$, \\ Gary Walford, MD ${ }^{7}$, Jeffrey P. Gold, MD $^{8}$, Craig R. Smith, MD $^{9}$, Desmond Jordan, MD ${ }^{10}$, \\ Robert S.D. Higgins, MD ${ }^{11}$, and Edward L. Hannan, PhD $^{2}$ \\ ${ }^{1}$ Penn State Hershey College of Medicine, Hershey PA \\ ${ }^{2}$ University at Albany, State University of New York, Rensselaer, NY \\ ${ }^{3}$ Drexel University College of Medicine, Philadelphia, PA \\ ${ }^{4}$ New York University Medical Center, New York, NY \\ ${ }^{5}$ University of Connecticut Health Center, Farmington, CT \\ ${ }^{6}$ St. Joseph's Health System, Atlanta, GA \\ 7Johns Hopkins Medical Center, Baltimore, MD \\ ${ }^{8}$ University of Toledo, Toledo, $\mathrm{OH}$ \\ ${ }^{9}$ Columbia University, New York, NY \\ ${ }^{10}$ Columbia University, New York, NY \\ ${ }^{11}$ Ohio State University, Columbus, $\mathrm{OH}$
}

\begin{abstract}
Background-Few studies have examined differences in long-term mortality between coronary artery bypass graft surgery and stenting with drug-eluting stents (DES) for multivessel disease without left main coronary artery stenosis. This study compares the risks of long-term mortality between these 2 procedures during a follow-up of up to 5 years.
\end{abstract}

\begin{abstract}
Methods-Patients who underwent isolated bypass surgery $(n=13,212)$ and stenting with DES $(n=20,161)$ between October 2003 and December 2005 in New York State were followed for their vital status through 2008. To control for treatment selection bias, bypass and stenting patients were matched on age, number of diseased coronary vessels, presence of proximal or nonproximal left anterior descending (LAD) artery disease, and propensity of undergoing bypass surgery. Fiveyear survival rates for the 2 procedures were compared and hazard ratios for death of bypass surgery compared to stenting were obtained.
\end{abstract}

Results-The respective 5-year survival rates in the 8,121 pairs of matched bypass and stenting patients were $80.4 \%$ and $73.6 \%(\mathrm{P}<0.001)$, and the risk of death following bypass surgery was

(C) 2012 The Society of Thoracic Surgeons. Published by Elsevier Inc. All rights reserved.

Corresponding Author: Chuntao Wu, MD, PhD,Penn State Hershey College of Medicine, 600 Centerview Dr., ASB 2200, A210, Hershey, PA 17033, cwupub@gmail.com, Tel: 717-531-4209, Fax: 717-531-5779.

Publisher's Disclaimer: This is a PDF file of an unedited manuscript that has been accepted for publication. As a service to our customers we are providing this early version of the manuscript. The manuscript will undergo copyediting, typesetting, and review of the resulting proof before it is published in its final citable form. Please note that during the production process errors may be discovered which could affect the content, and all legal disclaimers that apply to the journal pertain. 
$29 \%$ lower than for stenting (hazard ratio $=0.71,95 \%$ confidence interval: $0.67-0.77, \mathrm{P}<0.001$ ). Significantly lower risks of death for bypass surgery were observed in patients with LAD artery disease but not in patients without LAD artery disease. Significantly lower risks of death for bypass surgery were also found in all patient subgroups defined by the presence of selected baseline risk factors.

Conclusions-Bypass surgery is associated with lower risk of death than stenting with DES for multivessel disease without left main stenosis.

\section{Keywords}

CABG; stents; outcomes

\section{INTRODUCTION}

The comparative effectiveness of coronary artery bypass graft (CABG) surgery and percutaneous coronary intervention (PCI) has been an important research topic in the management of severe coronary artery disease. A number of randomized clinical trials[1-6] and observational studies[7-15] have consistently reported that CABG surgery is associated with a lower risk of repeat revascularization compared to PCI with stenting, but the relative benefits reported in long-term survival between these 2 procedures have been inconsistent across studies. Moreover, only a few of these studies included patients with implantation of drug-eluting stents (DES) [1, 2, 12-15].

In a previous study, we examined the difference in 18-month survival between CABG and DES patients for multi-vessel disease without left main coronary artery (LMCA) stenosis [12]. Considering that the relative benefit in survival between these 2 procedures may change over time, we compared the risks of death following these procedures in a larger study population for a 5-year follow-up period and evaluated the relative risks of death across patient subgroups in this study.

\section{MATERIAL AND METHODS}

\section{Databases}

The patients included in this study were identified from New York State's Cardiac Surgery Reporting System (CSRS) and Percutaneous Coronary Intervention Reporting System (PCIRS). For each cardiac surgery and PCI patient in non-federal hospitals in New York State, demographics, pre-procedural risk factors, procedural information, post-procedural complications, and discharge status are entered into the CSRS and the PCIRS, respectively, by data coordinators in the participating hospitals.

Another database used in this study was the National Death Index, which contains all death records in the United States. It was used to determine the vital status of each patient in this study. Patients' social security numbers, dates of birth, and sex were used to link to the National Death Index to determine if they died during the follow-up period.

\section{Study Population}

Patients who underwent isolated CABG surgery without other major concomitant cardiac procedures or stenting with implantation of DES (with or without implantation of bare-metal stents (BMS)) between October 1, 2003 and December 31, 2005 in New York State were included in this study if the patients (1) had no history of coronary revascularization prior to the index procedure, (2) had at least 2 diseased major epicardial coronary arteries in which the degree of stenosis was $270 \%$, (3) had no diseased LMCA in which the degree of 
stenosis was $\geq 50 \%$, and (4) did not suffer a myocardial infarction (MI) within 24 hours preceding the index procedure. A total of 13,212 CABG patients and 20,161 stent patients met the inclusion criteria and were included in this study.

\section{Outcome}

The outcome of interest is all-cause mortality after the index procedure until the end of follow-up on December 31, 2008. The median length of follow-up from the date of procedure to either death or the end of follow-up was 3.9 years with an interquartile range of $3.4-4.6$ years, and the longest length of follow-up was 5.3 years.

\section{Statistical Analysis}

The distributions of baseline risk factors for the CABG and the stent patients were summarized as percentages for categorical variables and as means for continuous variables, respectively; and were compared using Pearson's chi-square test and Student's t-test, respectively. The significance of the difference in survival between CABG surgery and stent patients was then examined by using the log-rank test. Differences in survival were also examined in 5 anatomic subgroups of patients who had (1) three diseased vessels with proximal LAD artery disease, (2) three diseased vessels with non-proximal LAD artery disease, (3) two diseased vessels with proximal LAD artery disease, (4) two diseased vessels with non-proximal LAD artery disease, and (5) two diseased vessels without LAD artery disease, respectively.

Because this study is observational and baseline risk factors were not distributed equally between the CABG and the stent patients, a propensity-matched analysis was then conducted to control for treatment selection bias. First, a logistic regression model was fit using all available patient risk factors listed in Table 1 as independent variables to predict the probability of receiving CABG surgery instead of stenting. The $\mathrm{C}$ statistic of this model was 0.821 . Next, the CABG and stent patients were matched in a 1:1 ratio on age (difference $<2$ years), the number of diseased coronary arteries, the presence of diseased proximal or non-proximal LAD artery, and the propensity score (the log-odds of the predicted probability of being treated with CABG surgery). A CABG-stent pair of patients was considered to be a match in the propensity analysis if the difference in propensity scores was $\$$ ). 3 times the standard deviation of the propensity scores in the study population. Then, for the matched patients, the standardized differences in proportions of categorical risk factors and in means of continuous risk factors were computed to evaluate if the baseline risk factors were evenly distributed.

The differences in survival between CABG surgery and stenting with DES in the entire matched patient population and in the patients in the 5 anatomic groups were tested for significance using the log-rank test. The overall hazard ratio for death for CABG surgery in comparison to stenting was obtained by fitting a Cox proportional hazards regression model in which the clustering of patients within matched pairs was accounted for using a robust sandwich estimator[16]. Also, anatomic group-specific hazard ratios were obtained and the significance of the interaction between treatment (CABG surgery or stenting) and anatomic groups was tested to assess if the relative risk of death during follow-up between CABG surgery and stenting was different across anatomic groups. Furthermore, the statistical significances of interactions between treatment and baseline risk factors such as age, sex, ejection fraction, history of MI, cerebrovascular disease, peripheral arterial disease, congestive heart failure, and diabetes were tested using Cox proportional hazards models adjusting for significant $(\mathrm{P}<0.05)$ risk factors for mortality.

All statistical analyses were conducted in SAS version 9.3 (SAS Institute, Cary, NC). 


\section{RESULTS}

Table 1 shows that compared to the stent patients, the CABG patients were slightly older on average, more likely to be in the age group of 60-79 years, but less likely to be younger than 60 years or at least 80 years old. The CABG patients were also more likely to be male and non-Hispanic White, have 3 diseased coronary arteries, have ejection fractions $<50 \%$, be hemodynamically unstable, and have comorbidities such as cerebrovascular disease, peripheral arterial disease, congestive heart failure, malignant ventricular arrhythmia, chronic obstructive pulmonary disease, diabetes, and renal failure.

The propensity matching resulted in 8,121 pairs of CABG and stent patients. Table 1 shows that the distributions of baseline risk factors between the 2 groups of matched patients were comparable. The standardized differences in the prevalences or means of baseline risk factors were $\leq 2.3 \%$ and none was statistically significant.

Among the 13,212 CABG and the 20,161 DES patients, 2,173 and 3,407 died during followup through December 31, 2008, respectively. Figure 1A shows that the 1-year survival rate for CABG surgery was $1.0 \%$ lower than stenting with DES (94.9\% vs. $95.9 \%, \mathrm{P}<0.001)$, but the 5-year survival rate for CABG surgery was $2.5 \%$ higher ( $78.5 \%$ vs. $76.0 \%, \mathrm{P}=0.005$ ). Similar patterns of crossing survival curves were observed in the 4 anatomic subgroups involving a diseased LAD artery (Figures 1B-1E), and the 5-year survival rates for CABG surgery were significantly higher in the patients who had three diseased vessels with proximal LAD artery disease (78.1\% vs. $71.3 \%, \mathrm{P}<0.001$, Figure $1 \mathrm{~B})$ and in the patients who had two diseased vessels with non-proximal LAD artery disease $(80.8 \%$ vs. $77.3 \%$, $\mathrm{P}=0.02$, Figure $1 \mathrm{E})$. However, Figure $1 \mathrm{~F}$ shows that the survival rate for $\mathrm{CABG}$ surgery was consistently lower than stenting with DES in the entire follow-up period.

Among the 8,121 pair-matched patients, there were 1,183 and 1,549 deaths in the CABG and stent groups, respectively, during the follow-up through 2008. Figure 2A shows that the difference in survival between CABG surgery and stenting with DES was not statistically significant at 1 year. By year 2 the survival advantage for CABG surgery was $1.6 \%(93.4 \%$ vs. $91.8 \%, \mathrm{P}<0.001)$, and the difference in survival increased to $6.8 \%(80.4 \%$ vs. $73.6 \%$, $\mathrm{P}<0.001$ ) by year 5 . Figures $2 \mathrm{~B}-2 \mathrm{E}$ show that the 5 -year survival rates for $\mathrm{CABG}$ surgery were significantly higher the 4 anatomic subgroups involving a diseased LAD artery (all $\mathrm{P}$ values $\leq 0.002$ ). Figure $2 \mathrm{~F}$ shows that no survival advantage was found for $\mathrm{CABG}$ surgery in patients with 2-vessel disease without LAD artery disease ( $74.6 \%$ vs. $73.4 \%, \mathrm{P}=0.66$ ).

Table 2 shows that the overall risk of death in the $\mathrm{CABG}$ patients was $29 \%$ lower $(\mathrm{HR}=0.71$, 95\% CI: 0.67-0.77, P<0.001). In addition, it shows that the risks of death for CABG surgery were significantly lower in the 4 anatomic subgroups involving a diseased LAD artery (all $\mathrm{P}$ values for HRs $<0.001$ ), but not in the group of 2-vessel disease without LAD artery disease $(\mathrm{HR}=0.91,95 \%$ CI: 0.69-1.21, $\mathrm{P}=0.53)$. However, the interaction between treatment and anatomic groups was not statistically significant $(\mathrm{P}=0.08)$, indicating that there was not definitive evidence to conclude that the relative risk of death between CABG surgery and stenting was different across the 5 anatomical groups.

Table 3 shows that higher crude 5-year survival rates for CABG surgery were consistently found in all predefined subgroups of the propensity-matched patients (all $\mathrm{P}$ values $<0.01$ ). Controlling for patient risk factors, lower adjusted risks of death for CABG surgery were observed in all subgroups, and the hazard ratios ranged from 0.59 to 0.84 (all $\mathrm{P}$ values < $0.05)$. The interaction between treatment and age was statistically significant $(\mathrm{P}=0.01)$ indicating that younger patients were associated with stronger relative risk reduction for $\mathrm{CABG}$ surgery compared to stenting than older patients. Also, the interaction between treatment and sex was statistically significant $(\mathrm{P}=0.01)$ suggesting that the relative risk 
reduction associated with CABG surgery was even stronger in male patients. The interactions between treatment and other examined baseline risk factors were not statistically significant, indicating that there was no evidence that the relative risks of death for CABG surgery compared to stenting were different across patient subgroups.

\section{COMMENT}

In this propensity-matched study, we found that the overall 5-year survival rate for CABG surgery was $6.8 \%$ higher than stenting with DES $(80.4 \%$ vs. $73.6 \%, \mathrm{P}<0.001)$ and the risk of dying during follow-up was $29 \%$ lower for CABG surgery ( $\mathrm{HR}=0.71, \mathrm{P}<0.001)$ in patients with multivessel disease but without left main coronary disease. Expanding on our previous study that had a follow-up period of 18 months [12], this long-term study with a larger sample size found that the survival advantage for $\mathrm{CABG}$ surgery widened over time.

The observed overall advantage in survival for CABG surgery in this study is consistent with the results of some studies that evaluated long-term risk of death following CABG surgery and stenting with DES. For instance, the Synergy between PCI with Taxus and Cardiac Surgery trial (SYNTAX) found that the 4-year survival rate for CABG surgery was higher than the rate for stenting with Taxus (paclitaxel-eluting) stents $(92.7 \%$ vs. $88.1 \%$, $\mathrm{P}=0.01$ ) in patients with 3-vessel disease[2], though the differences in survival were not significantly different during first 3-years of follow-up[17]. ENREF 30 In a large multicenter observational study, Weintraub et al found that CABG surgery was associated with a $21 \%$ (HR=0.79, 95\% CI: 0.76-0.82) lower risk of death during 4-year follow-up in the elderly who were at least 65 years old and enrolled in the Medicare's fee-for-services program [15]. Similarly, in a single-center study of 3,720 patients, Li et al reported a $36 \%$ lower risk for CABG surgery in 3-year follow-up $(\mathrm{HR}=0.64, \mathrm{P}=0.03)$ [13]. On the other hand, other studies[14, 18] including the comparison of DES cases to historical CABG cases in the Arterial Revascularization Therapies Study - Part II (ARTS II) trial[14] did not find an overall survival advantage for CABG surgery, though CABG surgery was found related to lower risk of major adverse cardiovascular and cerebrovascular events $[14,18]$.

In addition, we found that CABG surgery was associated with lower risk of death compared to stenting with DES across a number of patient subgroups. Such findings are consistent with the study by Weintraub et al[15]. Unlike the similar risk reductions associated with CABG surgery in patients $65-74$ years old $(\mathrm{HR}=0.77,95 \% \mathrm{CI}$ : $0.73-0.81)$ and 75 years or older (HR=0.78, 95\% CI: 0.74-0.82) observed in the Weintruab study[15], we found that the risk reductions were significantly different across age groups and the weakest was found in patients who were at least 80 years old. We also found that the risk reduction was significantly stronger in men than in women.

This study has a few strengths. First, it is a large population-based observational study using real-world data so that its results are more likely to be generalizable to other patient populations than randomized controlled trials, in which a large proportion of patients are usually excluded because they do not meet the enrollment criteria. For example, 58\% of the "all-comers" in the SYNTAX trial were excluded from randomization[1]. Second, the data are of high quality because of the quality assurance measures undertaken in the data collection, matching and auditing processes. Third, the National Death Index was used to ascertain the patients' vital status, so the chance of loss to follow-up is minimized.

This study also has limitations. First, as in all observational studies, treatment selection is of concern. To address this issue, we conducted a propensity-matched analysis. Nevertheless, there are unmeasured risk factors (e.g., frailty, cancer) that may not be balanced between the 2 treatment groups. However, it is unlikely that the inability to control for unmeasured risk 
factors is responsible for the observed survival advantage for CABG surgery. The reason is that in the unmatched patients, the 1-year survival rate was actually higher for stenting with DES than CABG surgery ( $95.9 \%$ vs. $94.9 \%, \mathrm{P}=0.005$, Figure $1 \mathrm{~A}$ ). This survival advantage for stenting in the first 2.5 years of follow-up is consistent with the findings that the prevalences of comorbidities were lower in the unmatched stenting patients and does not support an alternative explanation that stenting cases were more severe and at higher risk of death at baseline. Second, the anatomic complexity of coronary disease was measured based on number of vessels diseased and stenosis in proximal LAD artery in this study. The SYNTAX score can better characterize the complexity of lesions [19], but it was not available to us. Third, this study included the patients operated on in the first 3 years after the first generation DES was approved in the U.S., and the practices of both CABG surgery and stenting have been continuously improving. Therefore the comparative effectiveness of the 2 procedures could have changed over time.

\section{Acknowledgments}

We thank the New York State Cardiac Advisory Committee for their encouragement and support of this study; and Kimberly Cozzens, Cynthia Johnson, Rosemary Lombardo, and the cardiac catheterization laboratories and cardiac surgery programs of the participating hospitals for their tireless efforts to ensure the timeliness, completeness, and accuracy of the registry data.

This work was supported by the National Institutes of Health (RC1HL099122).

\section{References}

1. Serruys PW, Morice M-C, Kappetein AP, et al. Percutaneous coronary intervention versus coronaryartery bypass grafting for severe coronary artery disease. N Engl J Med. 2009; 360:961-72. [PubMed: 19228612]

2. Mohr FW, Suttorp M, van Boven WJ, et al. Four-year follow-up of the SYNTAX trial: Optimal revascularization atrategy in paitents with three-vessel disease (Abstract). J Am Coll Cardiol. 2011; 58:B8.

3. Booth J, Clayton T, Pepper J, et al. Randomized, controlled trial of coronary artery bypass surgery versus percutaneous coronary intervention in patients with multivessel coronary artery disease - Sixyear follow-up from the stent or surgery trial (SoS). Circulation. 2008; 118:381-8. [PubMed: 18606919]

4. Hueb W, Lopes N, Gersh BJ, et al. Ten-year follow-up survival of the Medicine, Angioplasty, or Surgery Study (MASS II) A randomized controlled clinical trial of 3 therapeutic strategies for multivessel coronary artery disease. Circulation. 2010; 122:949-57. [PubMed: 20733102]

5. Rodriguez AE, Baldi J, Pereira CF, et al. Five-year follow-up of the argentine randomized trial of coronary angioplasty with stenting versus coronary bypass surgery in patients with multiple vessel disease (ERACI II). J Am Coll Cardiol. 2005; 46:582-8. [PubMed: 16098419]

6. Serruys PW, Ong ATL, van Herwerden LA, et al. Five-year outcomes after coronary stenting versus bypass surgery for the treatment of multivessel disease - The final analysis of the arterial revascularization therapies study (ARTS) randomized trial. J Am Coll Cardiol. 2005; 46:575-81. [PubMed: 16098418]

7. Hannan EL, Racz MJ, Walford G, et al. Long-term outcomes of coronary-artery bypass grafting versus stent implantation. N Engl J Med. 2005; 352:2174-83. [PubMed: 15917382]

8. Malenka DJ, Leavitt BJ, Hearne MJ, et al. Comparing long-term survival of patients with multivessel coronary disease after CABG or PCI - Analysis of BARI-like patients in northern New England. Circulation. 2005; 112:I371-I6. [PubMed: 16159849]

9. Bair TL, Muhlestein JB, May HT, et al. Surgical Revascularization is associated with improved long-term outcomes compared with percutaneous stenting in most subgroups of patients with multivessel coronary artery disease - Results from the intermountain heart registry. Circulation. 2007; 116:I226-I31. [PubMed: 17846308] 
10. Javaid A, Steinberg DH, Buch AN, et al. Outcomes of coronary artery bypass grafting versus percutaneous coronary intervention with drug-eluting Stents for patients with multivessel coronary artery disease. Circulation. 2007; 116:I200-I6. [PubMed: 17846304]

11. Wu C, Zhao S, Wechsler AS, et al. Long-term mortality of coronary artery bypass grafting and bare-metal stenting. The Annals of thoracic surgery. 2011; 92:2132-8. [PubMed: 22014747]

12. Hannan EL, Wu C, Walford G, et al. Drug-eluting stents vs. coronary-artery bypass grafting in multivessel coronary disease. The New England journal of medicine. 2008; 358:331-41. [PubMed: 18216353]

13. Li Y, Zheng Z, Xu B, et al. Comparison of drug-eluting stents and coronary artery bypass surgery for the treatment of multivessel coronary disease: three-year follow-up results from a single institution. Circulation. 2009; 119:2040-50. [PubMed: 19349321]

14. Serruys PW, Onuma Y, Garg S, et al. 5-year clinical outcomes of the ARTS II (Arterial Revascularization Therapies Study II) of the sirolimus-eluting stent in the treatment of patients with multivessel de novo coronary artery lesions. J Am Coll Cardiol. 2010; 55:1093-101. [PubMed: 20171036]

15. Weintraub WS, Grau-Sepulveda MV, Weiss JM, et al. Comparative effectiveness of revascularization strategies. N Engl J Med. 2012; 366:1467-76. [PubMed: 22452338]

16. Lin DY, Wei LJ. The robust inference for the Cox proportional hazards model. Journal of the American Statistical Association. 1989; 84:1074-8.

17. Kappetein AP, Feldman TE, Mack MJ, et al. Comparison of coronary bypass surgery with drugeluting stenting for the treatment of left main and/or three-vessel disease: 3-year follow-up of the SYNTAX trial. Eur Heart J. 2011; 32:2125-34. [PubMed: 21697170]

18. Yan TD, Padang R, Poh C, et al. Drug-eluting stents versus coronary artery bypass grafting for the treatment of coronary artery disease: a meta-analysis of randomized and nonrandomized studies. $\mathrm{J}$ Thorac Cardiovasc Surg. 2011; 141:1134-44. [PubMed: 21167508]

19. Sianos G, Morel MA, Kappetein AP, et al. The SYNTAX Score: an angiographic tool grading the complexity of coronary artery disease. EuroIntervention: journal of EuroPCR in collaboration with the Working Group on Interventional Cardiology of the European Society of Cardiology. 2005; 1:219-27. [PubMed: 19758907] 

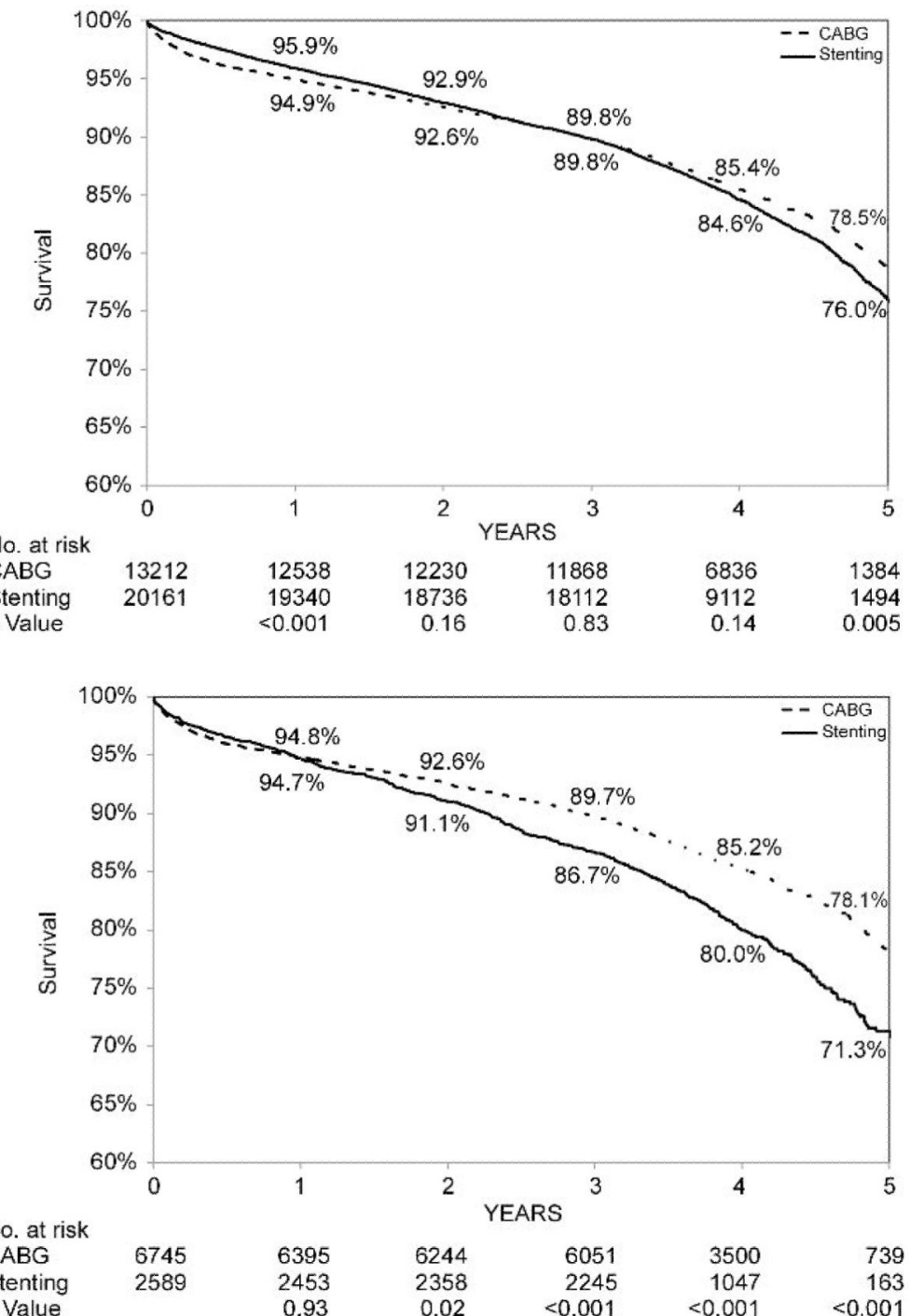

$\begin{array}{lrrrrrr}\text { No. at risk } & & & 6 & & & \\ \text { CABG } & 6745 & 6395 & 6244 & 6051 & 3500 & 739 \\ \text { Stenting } & 2589 & 2453 & 2358 & 2245 & 1047 & 163 \\ \text { p Value } & & 0.93 & 0.02 & <0.001 & <0.001 & <0.001\end{array}$

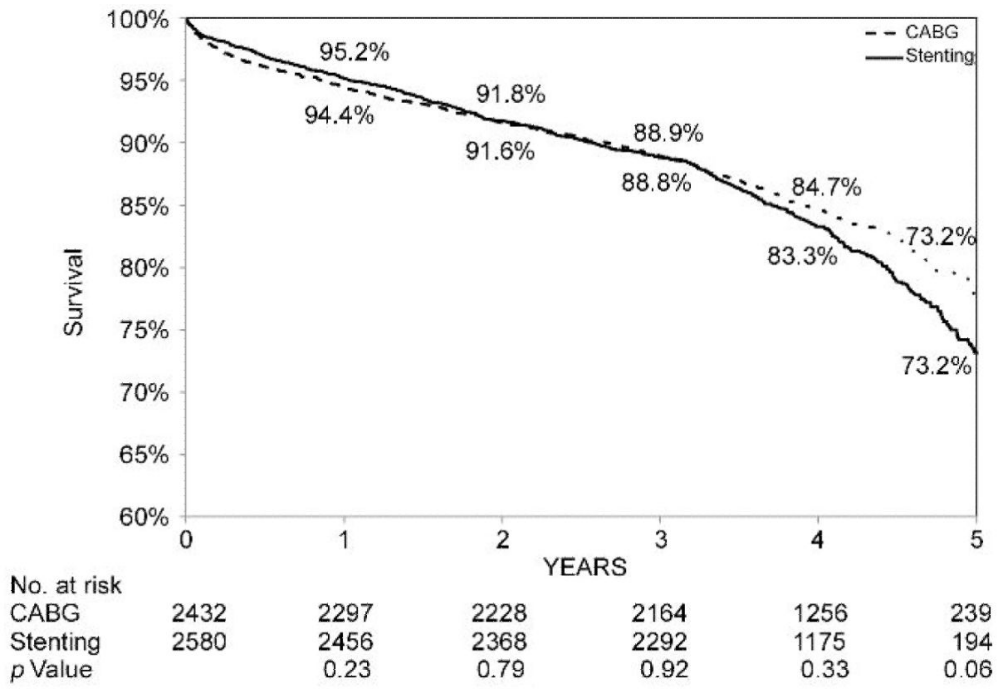

Ann Thorac Surg. Author manuscript; available in PMC 2014 April 01. 

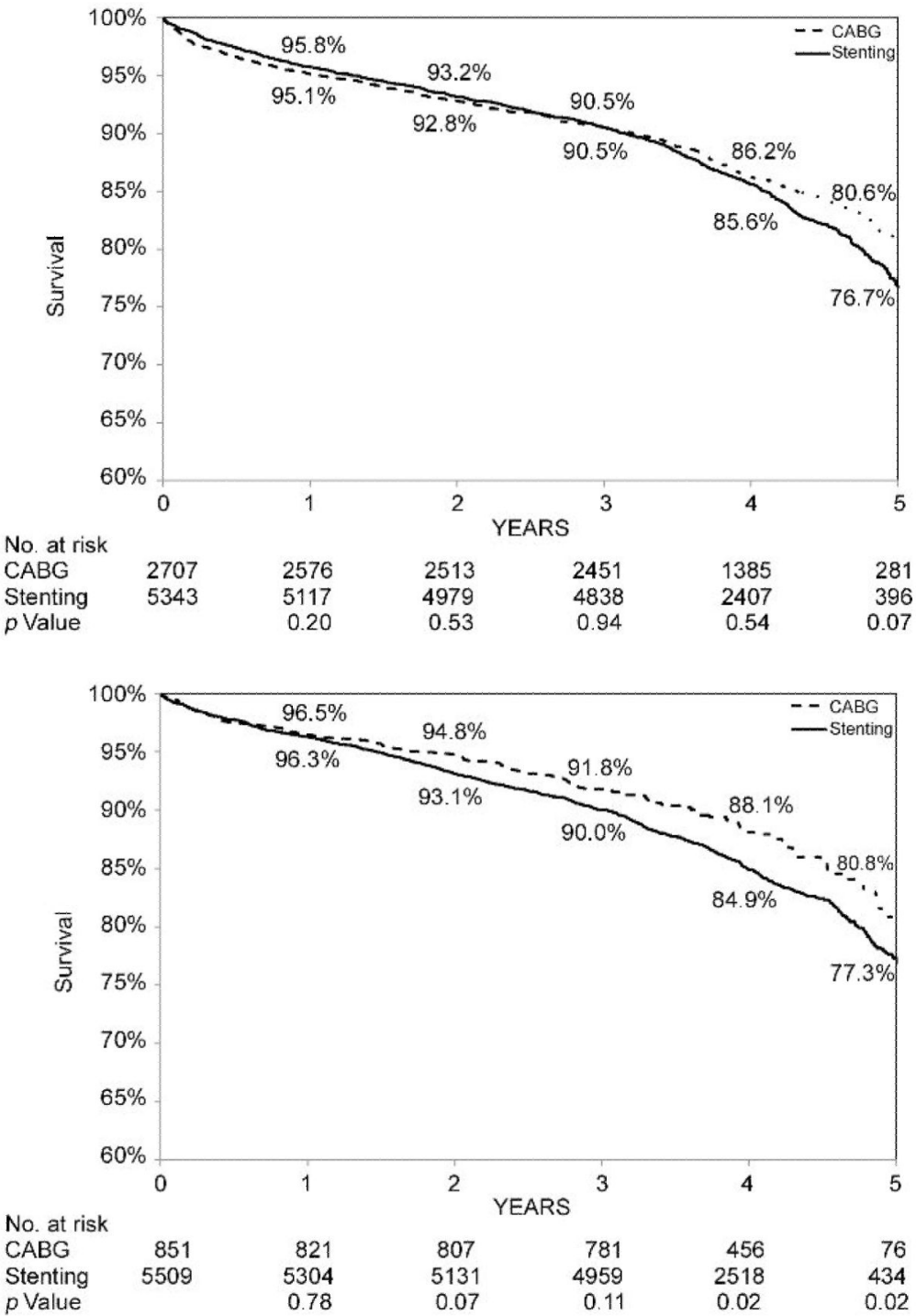


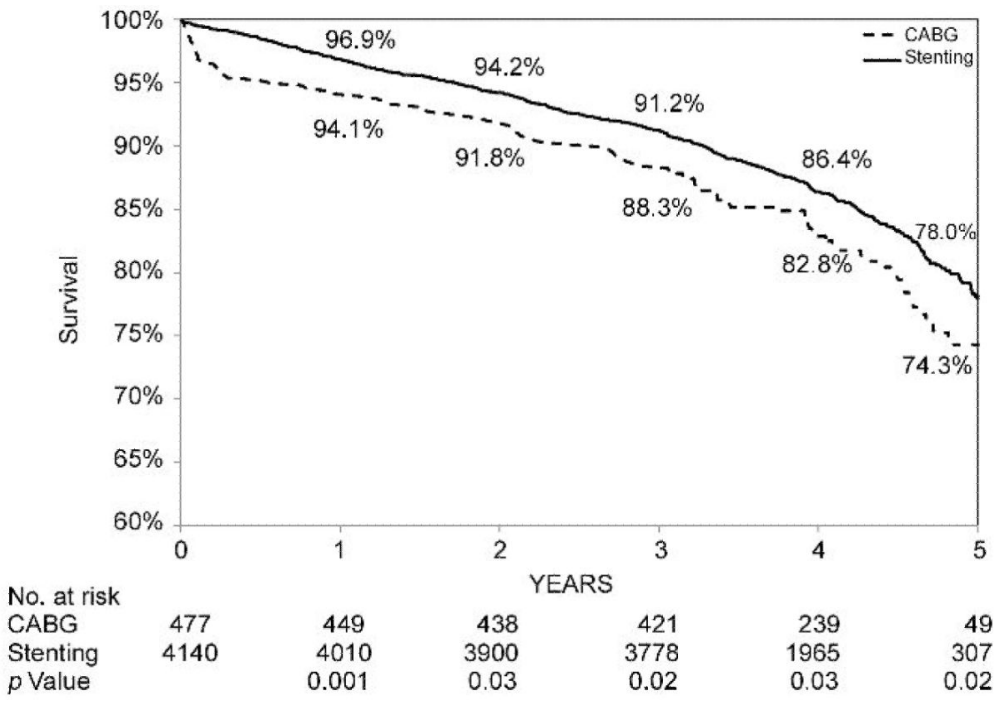

Figure 1.

(Panels A-F). Kaplan-Meier survival curves for CABG and stenting patients. (A), All patients, (B) three-diseased vessels with diseased proximal left anterior descending (LAD) artery, (C) three-diseased vessels with diseased non-proximal LAD artery, (D) two diseased vessels with diseased proximal LAD artery, $(\mathrm{E})$ two diseased vessels with diseased nonproximal LAD artery, and $(\mathrm{F})$ two diseased vessels without diseased LAD artery. 

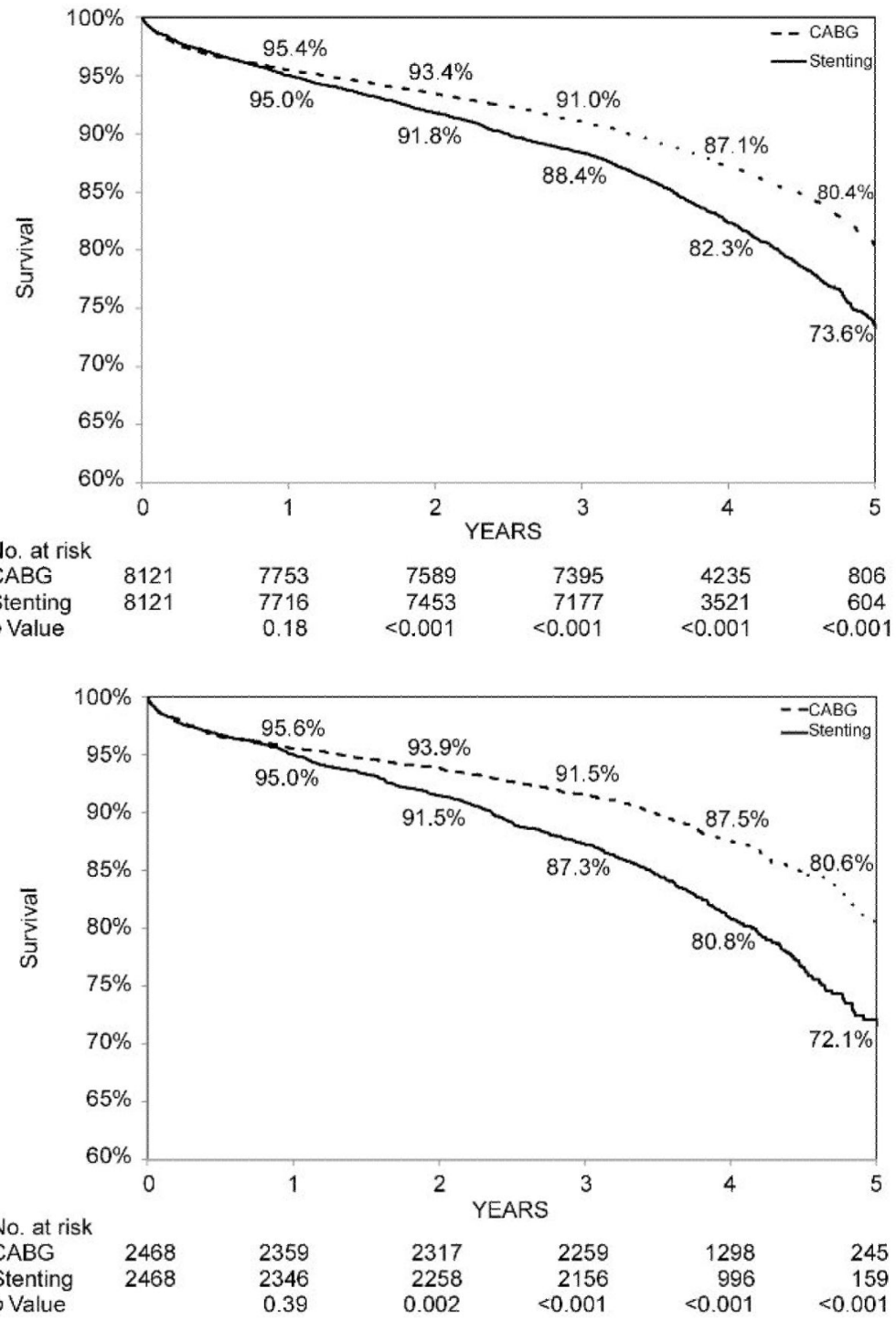

Ann Thorac Surg. Author manuscript; available in PMC 2014 April 01. 

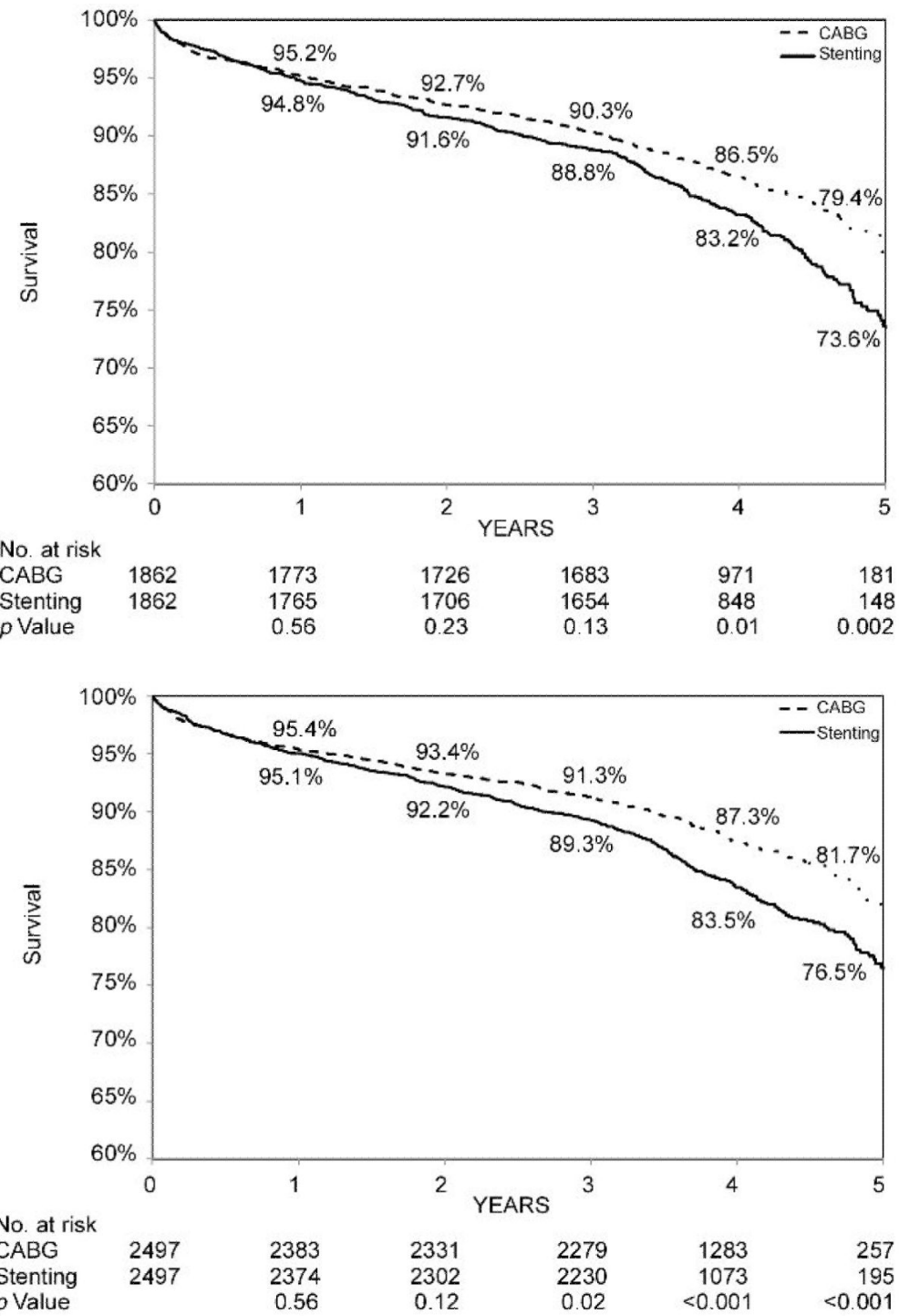

Ann Thorac Surg. Author manuscript; available in PMC 2014 April 01. 

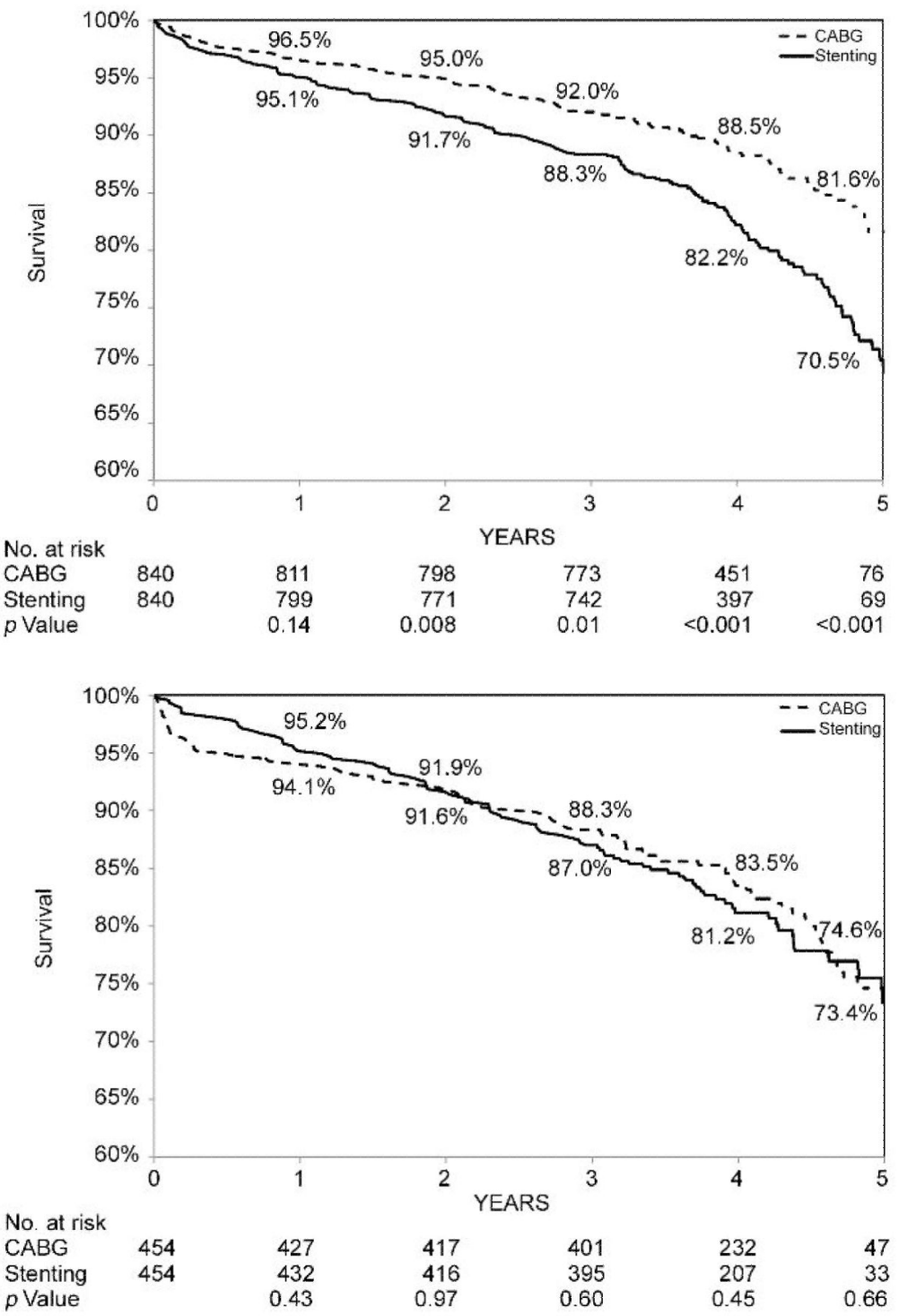

Figure 2.

(Panels A-F). Kaplan-Meier survival curves for propensity-matched CABG and stenting patients. Denotations of A-F, same as in Figure 1. 


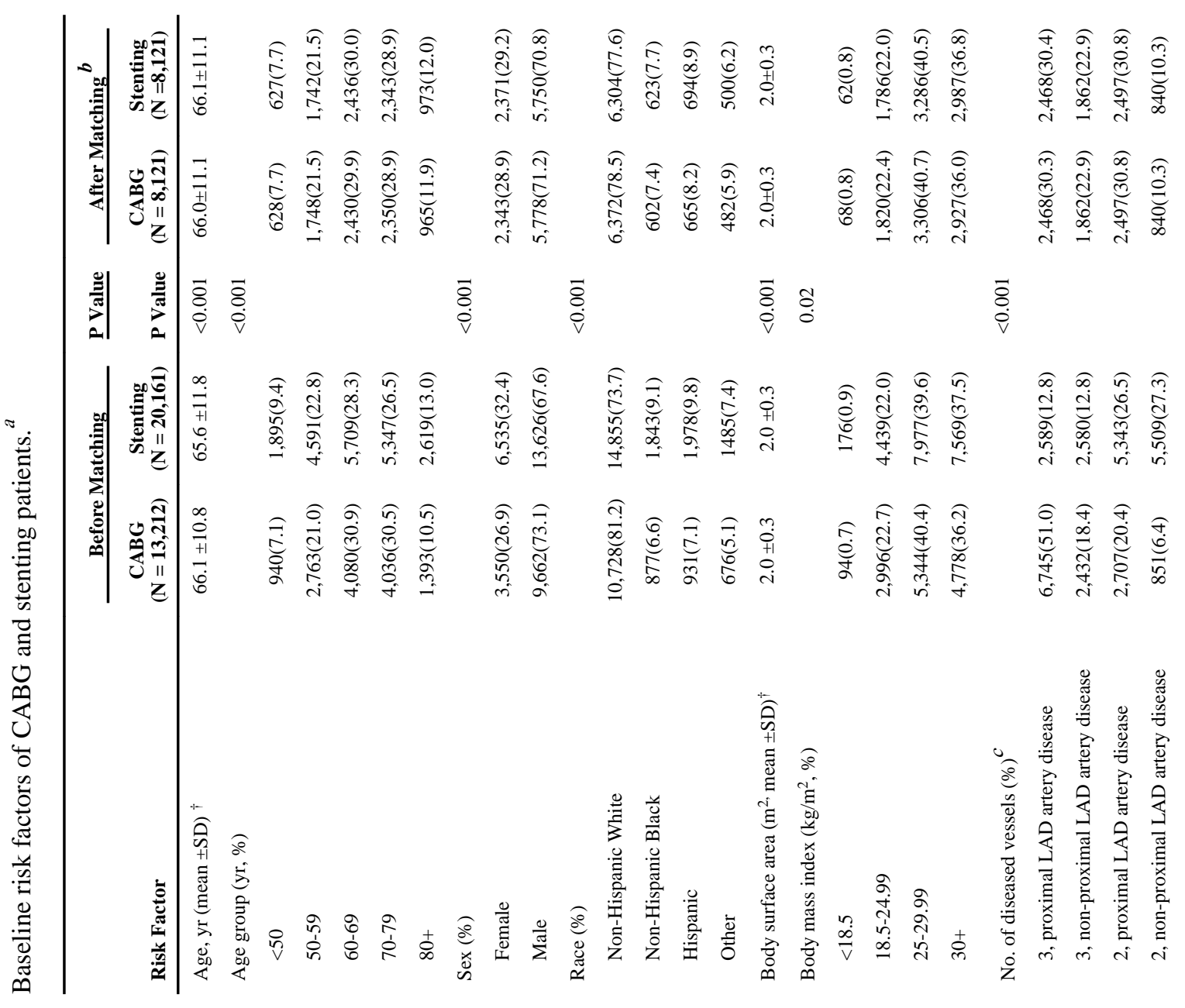




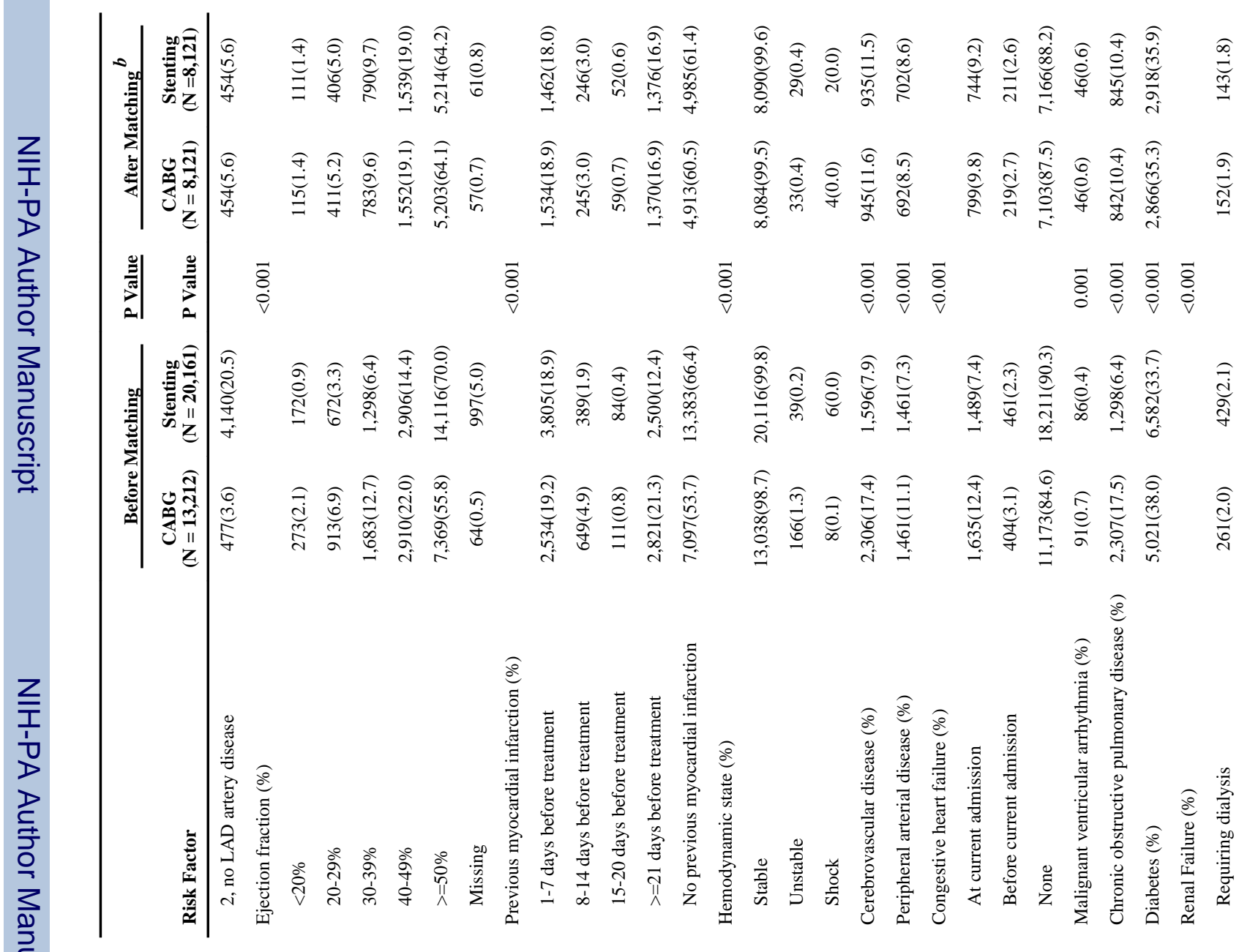




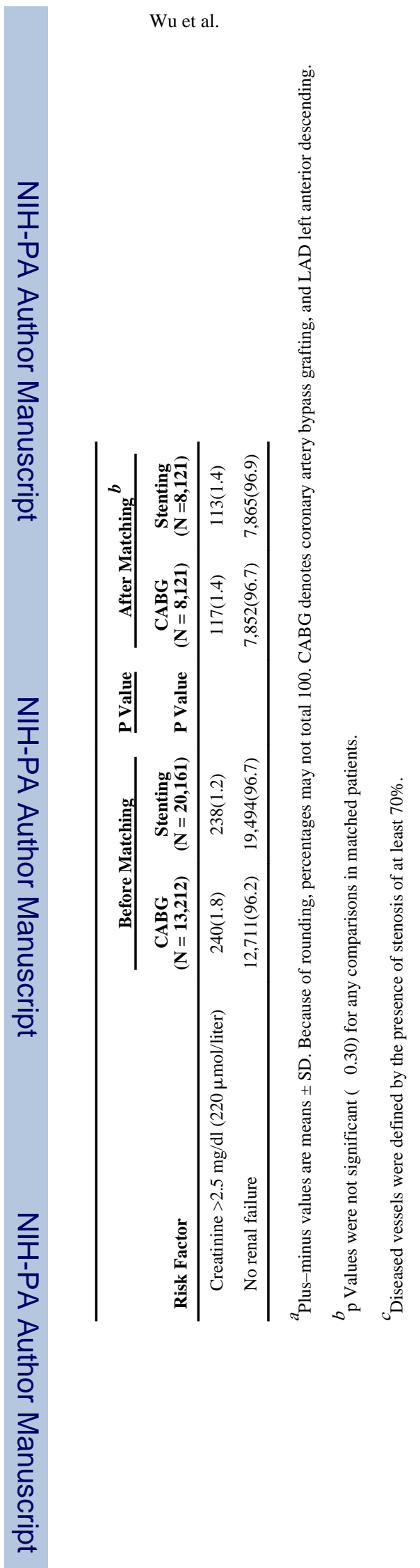

Ann Thorac Surg. Author manuscript; available in PMC 2014 April 01. 


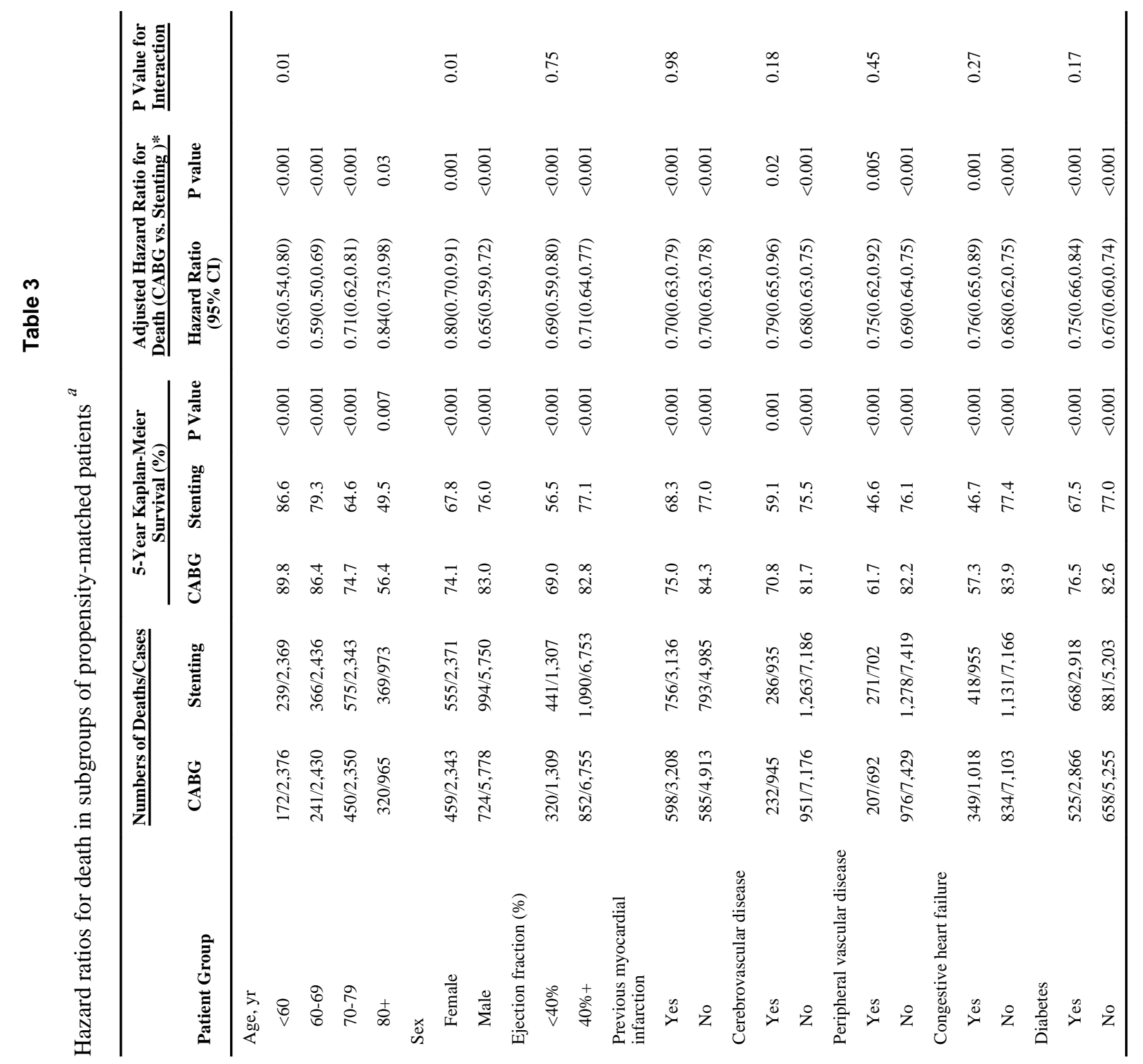


